\title{
Erratum to: Role of low-intensity laser therapy on naloxone- precipitated morphine withdrawal signs in mice: is nitric oxide a possible candidate mediator?
}

\author{
Reza Ojaghi • Hamid Sohanaki • Tayyeb Ghasemi • \\ Faeze Keshavarz • Mahmoud Yousefifard • \\ Hamid Reza Sadeghipour
}

Published online: 8 July 2014

(C) Springer-Verlag London 2014

Erratum to: Lasers Med Sci

DOI 10.1007/s10103-014-1530-7

The original version of this article, unfortunately, contained an error.

One of the author's name listed in the article was incorrectly captured. Hamidreza Sadeghipour's name should have been presented as Hamid Reza Sadeghipour and abbreviated to H. R. Sadeghipour.

The author's correct name is presented in this paper. In addition, M. Yousefifard is no longer affiliated to "Molecular Biology Department, Illinois Institute of Technology." His correct affiliation is given below.

The online version of the original article can be found at http://dx.doi.org/ 10.1007/s10103-014-1530-7.

\section{R. Ojaghi}

Molecular Biology Department, Illinois Institute of Technology,

Chicago, IL, USA

H. Sohanaki • T. Ghasemi $\cdot$ M. Yousefifard $\cdot$ H. R. Sadeghipour $(\square)$ Department of Physiology, School of Medicine, Tehran University of Medical Sciences, Poursina Ave, Enqelab Sq, Tehran 13145, Iran e-mail: Sohanaky@yahoo.com

\section{F. Keshavarz}

Veterinary Medicine Faculty, University of Tehran, Tehran, Iran 